\title{
Parental and household smoking and the increased risk of bronchitis, bronchiolitis and other lower respiratory infections in infancy: systematic review and meta-analysis
}

\author{
Laura L Jones ${ }^{1 *}$, Ahmed Hashim¹, Tricia McKeever', Derek G Cook², John Britton', Jo Leonardi-Bee
}

\begin{abstract}
Background: Passive smoke exposure increases the risk of lower respiratory infection (LRI) in infants, but the extensive literature on this association has not been systematically reviewed for nearly ten years. The aim of this paper is to provide an updated systematic review and meta-analysis of studies of the association between passive smoking and LRI, and with diagnostic subcategories including bronchiolitis, in infants aged two years and under.

Methods: We searched MEDLINE and EMBASE (to November 2010), reference lists from publications and abstracts from major conference proceedings to identify all relevant publications. Random effect pooled odds ratios (OR) with 95\% confidence intervals (Cl) were estimated.

Results: We identified 60 studies suitable for inclusion in the meta-analysis. Smoking by either parent or other household members significantly increased the risk of LRl; odds ratios (OR) were 1.22 (95\% Cl 1.10 to 1.35) for paternal smoking, 1.62 ( $95 \% \mathrm{Cl} 1.38$ to 1.89 ) if both parents smoked, and 1.54 (95\% Cl 1.40 to 1.69 ) for any household member smoking. Pre-natal maternal smoking (OR 1.24, 95\% Cl 1.11 to 1.38) had a weaker effect than post-natal smoking (OR 1.58, 95\% Cl 1.45 to 1.73). The strongest effect was on bronchiolitis, where the risk of any household smoking was increased by an OR of 2.51 (95\% Cl 1.96 to 3.21 ).

Conclusions: Passive smoking in the family home is a major influence on the risk of LRI in infants, and especially on bronchiolitis. Risk is particularly strong in relation to post-natal maternal smoking. Strategies to prevent passive smoke exposure in young children are an urgent public and child health priority.
\end{abstract}

\section{Background}

The 2006 US Surgeon General's report on the effects of involuntary exposure to tobacco smoke concluded that passive smoking was a cause of a range of diseases of children, including acute lower respiratory infection (LRI) [1]. Those conclusions were based in part on the results of a series of systematic reviews and metaanalyses first commissioned for a report by the UK Government Scientific Committee on Tobacco and Health $(\mathrm{SCOTH})[2]$, which were then updated for the Surgeon General report. The original meta-analysis of effects on

\footnotetext{
* Correspondence: laura.jones@nottingham.ac.uk

'UK Centre for Tobacco Control Studies, Division of Epidemiology and Public Health, University of Nottingham, Clinical Sciences Building, Nottingham City Hospital, Nottingham, NG5 1PB, UK

Full list of author information is available at the end of the article
}

LRI was published by Strachan and Cook in 1997 [3] and included papers published to 1996; the update for the Surgeon General, as well as an updated SCOTH report published in 2004 [4], included papers published to 2001 .

Since 2001, many more studies of this association have been published but have not as yet been subject to meta-analysis. We have therefore updated the original Strachan and Cook review and meta-analyses of the epidemiological data to provide contemporary estimates of the effect of passive smoking on LRI in infants in the first two years of life, and to use the larger evidence base to explore the effects of pre-natal and post-natal exposure, effects of smoking by either parent, both parents or by any household member, and the effects of

\section{C) Biomed Central}


passive smoking on subcategories of the LRI diagnostic group. The work was carried out as part of a more extensive review of the effects of passive smoking in children, for the Royal College of Physicians [5].

\section{Methods}

\section{Systematic review methods}

The search strategy employed in the original Strachan and Cook systematic review and meta-analysis [3] was repeated in the current study and included a comprehensive literature search of MEDLINE (1997 to November 2010) and EMBASE (1997 to November 2010), published reviews, reference lists from identified publications and abstracts from major conference proceedings (European Respiratory Society and American Thoracic Society). No restrictions on language were imposed during the searches, but in keeping with the original strategy we report only results from papers written and published in English [3]. Studies of passive smoking were selected by the MeSH heading tobacco smoke pollution and/or relevant text words in the title, keywords or abstract. We then combined the results from the searches with the studies identified and included in the previous review [3].

\section{Inclusion and exclusion criteria}

Two authors (AH \& TM, or AH \& JLB) independently reviewed the titles and abstracts identified from the searches, and identified all studies meeting the following inclusion criteria: (a) the design was a comparative epidemiological study (case-control, cross-sectional or cohort design); (b) LRI, pneumonia, bronchitis, bronchiolitis or acute respiratory infection, either by parental report or clinical diagnosis, was presented as an outcome; (c) passive smoke exposure was ascertained by self report and/or biochemical validation of parental smoking. We excluded studies that were not primary reports (such as systematic reviews and commentaries); or in which asthma, wheeze, proven infection with respiratory syncytial virus rather than clinically diagnosed bronchiolitis, or death from LRI were identified as the sole outcome; or in which the majority of infants in the study were over the age of two years. Following the title and abstract review, two of three researchers (LLJ, AH, and/or JLB) independently reviewed the full text, excluding irrelevant papers as appropriate. Disagreements were resolved through group discussion. Data relating to study design, methods, definition of LRI outcome, characteristics of reference group, ascertainment of passive smoke exposure, passive smoke source, and timing of exposure, location of study, and age of study population, were extracted using a previously piloted data extraction form and entered into a standardised database.

\section{Assessment of methodological quality}

Studies that met the inclusion criteria were independently scored for methodological quality using the Cochrane Collaboration Non-Randomized Studies Working Group recognised Newcastle-Ottawa Quality Assessment Scale [6] by two reviewers. This scale is based on three broad categories relating to the selection of the study sample (four points); the comparability of the sample groups (two points); and the ascertainment of either the exposure (for case-control (three points) and cross-sectional studies (two points)) or the outcome (for cohort studies (three points). Thus, cross-sectional studies were rated out of a total of eight points and case-control and cohort studies out of a total of nine points. A score of seven or more was chosen a priori to indicate high methodological quality.

\section{Statistical analysis}

Data were analyzed to yield effect estimates either using unadjusted (crude) odds ratios (OR) from extracted data from the publications, or where possible, adjusted ORs. Meta-analysis was carried out to estimate the effects on the risk of LRI of smoking by the mother only, father only, both parents, and any household member. Studies which clearly defined maternal smoking as pre- or postnatal were analysed separately. Random effects models [7] were used to calculate a pooled OR with $95 \%$ confidence intervals $(\mathrm{CI})$ because the effect estimates were expected to be heterogeneous due to differences in the populations and exposures in the studies. Heterogeneity between study estimates was assessed using established methods $\left(\mathrm{I}^{2}\right)$ [8]. To explore reasons for heterogeneity between the studies, sub-group analyses were used to assess the roles of disease outcome (LRI, pneumonia, bronchitis, bronchiolitis, or acute respiratory infection), study type (cohort, cross-sectional, or case-control), study publication date (pre versus post 1997), methodological quality (lower versus higher), and method of ascertainment of passive smoke exposure (self reported versus biochemical validation). Publication bias was assessed visually using a funnel plot for the association between exposure to household passive smoke and the risk of LRI. Data were analyzed using Review Manager, version 5.0.23 ((RevMan), Copenhagen, The Nordic Cochrane Centre, The Cochrane Collaboration). $P$ values less than 0.05 were considered statistically significant. This analysis was performed in accordance with the Meta-Analysis of Observational Studies in Epidemiology (MOOSE) guidelines [9].

\section{Results}

Our post 1997 literature searches identified an initial sample of 3236 papers, of which 132 were deemed eligible for further review on the basis of their title and 
abstract. One hundred and three of these studies were excluded after full text review because they were either: [a] not primary studies but editorials, letters or commentaries; [b] the majority of infants in the study sample were older than two years; [c] the definition of the outcome was not lower respiratory infection; or [d] there were insufficient or unusable data presented in the paper. We thus identified a total of 29 papers published between 1997 and the end of November 2010 which met our inclusion criteria of a comparative epidemiological study assessing passive smoke exposure and the risk of lower respiratory infection in infants less than two years of age. Of the 38 papers included in the original Strachan and Cook meta-analysis [3], seven did not meet our inclusion criteria, because wheeze was recorded as the primary outcome [10-15], or there were problems with recall bias [16]. We thus identified a total of 60 studies for inclusion in the present meta-analysis [see Additional file 1 and Figure 1].

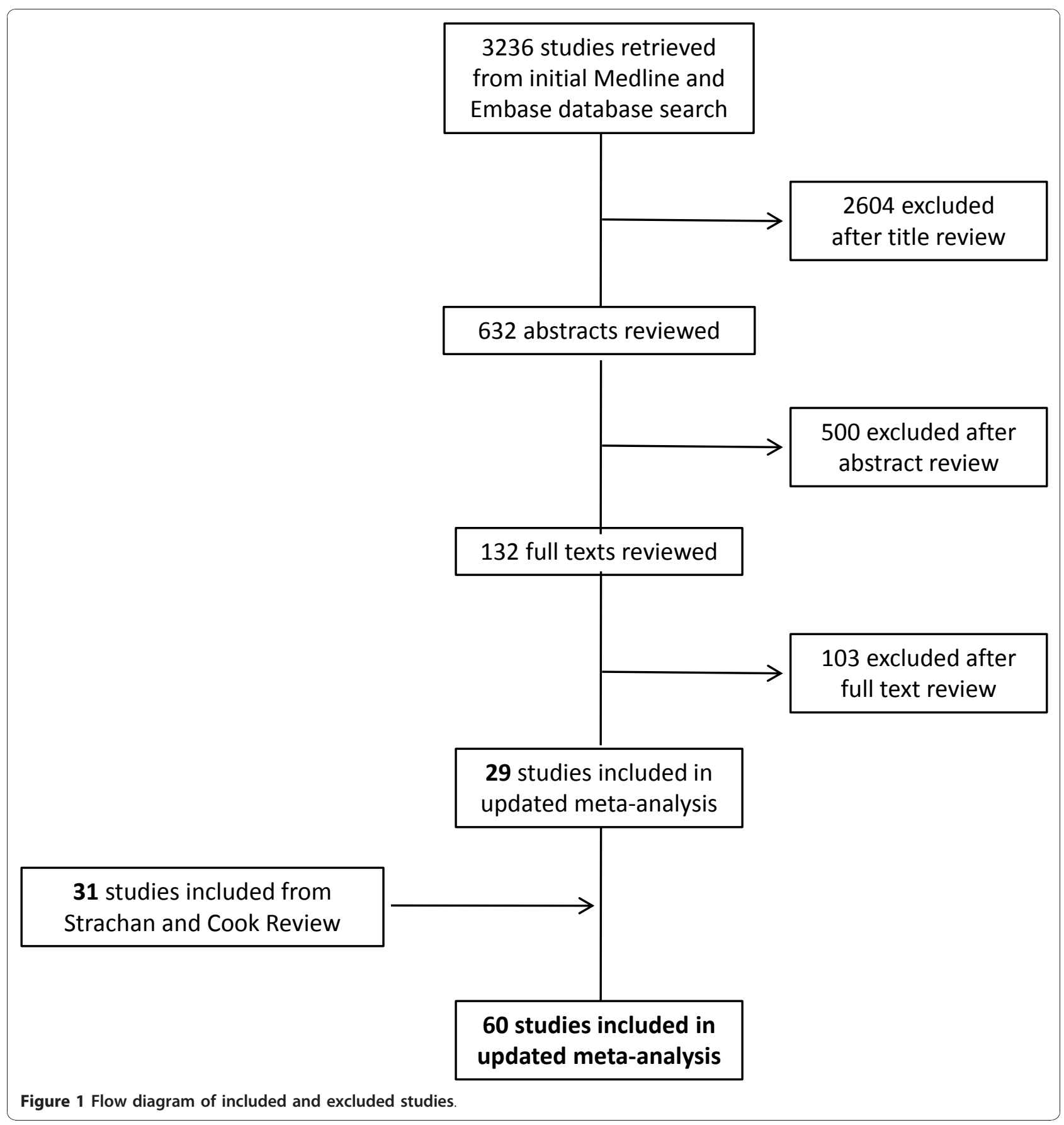


Over half of the included studies [17-47] used data from cohorts, primarily birth cohorts; 15 studies [48-62] used a case-control design and 13 studies [63-75] were crosssectional surveys. The LRI outcome reported was acute respiratory infection in seven studies $[19,23,31,42$, $61,63,72]$, bronchiolitis in ten studies [36,48-50,53,55, $56,59,64,73]$, bronchitis in ten studies [20,24,27,28,33,57, $66,70,71,76]$, pneumonia in three $[54,60,75]$, and in 30 studies the type of lower respiratory infection was not specified $[17,18,21,22,25,26,29,30,32,34,35,37-41,43-47,51$, $52,58,62,65,67-69,74]$. Studies measured infant exposure to passive smoke either by self-report [17-22,24-28, 30-34,36,38-40,42,43,45,47-51,53-57,59-72,74-76], independent observation [23], or by biochemically validated measures of nicotine metabolites such as cotinine $[35,37,41,44,46,52,58,73]$. Thirty studies $[17,18,24,25,29$, $34,35,38,40,43,46,48-50,52,53,56-62,66-70,75,76]$ adjusted for the infant's age in the analysis and 46 studies [17-22,24,26,28-35,37-39,43,45-50,52,56-71,73-75] adjusted for other potential confounding variables, such as breast feeding, maternal age, infant gender, allergy status, socioeconomic status, and maternal education.

\section{Methodological quality of studies and publication bias}

The methodological quality of the 60 studies included in the meta-analysis, as judged by the Newcastle-Ottawa scale score, is presented in Additional file 1. The overall median score was six (range three to nine). Using the a priori chosen cut of seven to indicate high methodological quality, we judged 20 of the studies to be of high quality; and the remaining 40 to be of lower quality primarily due to a combination of a lack of biochemical validation of passive smoke exposure, lack of representativeness of the study sample, and/or lack of adjusted analyses. There was no evidence of publication bias identified from funnel plots. The funnel plot for any household exposure and the risk of LRI is presented in Figure 2.

\section{Effects of any household member smoking}

Exposure to smoking by any household member was associated with a statistically significant increase in the odds of LRI for infants under the age of two years, by 1.54 (95\% CI 1.40 to $1.69 ; 37$ studies; Figure 3$)$. Moderate levels of heterogeneity $\left(I^{2}\right)$ were seen in the

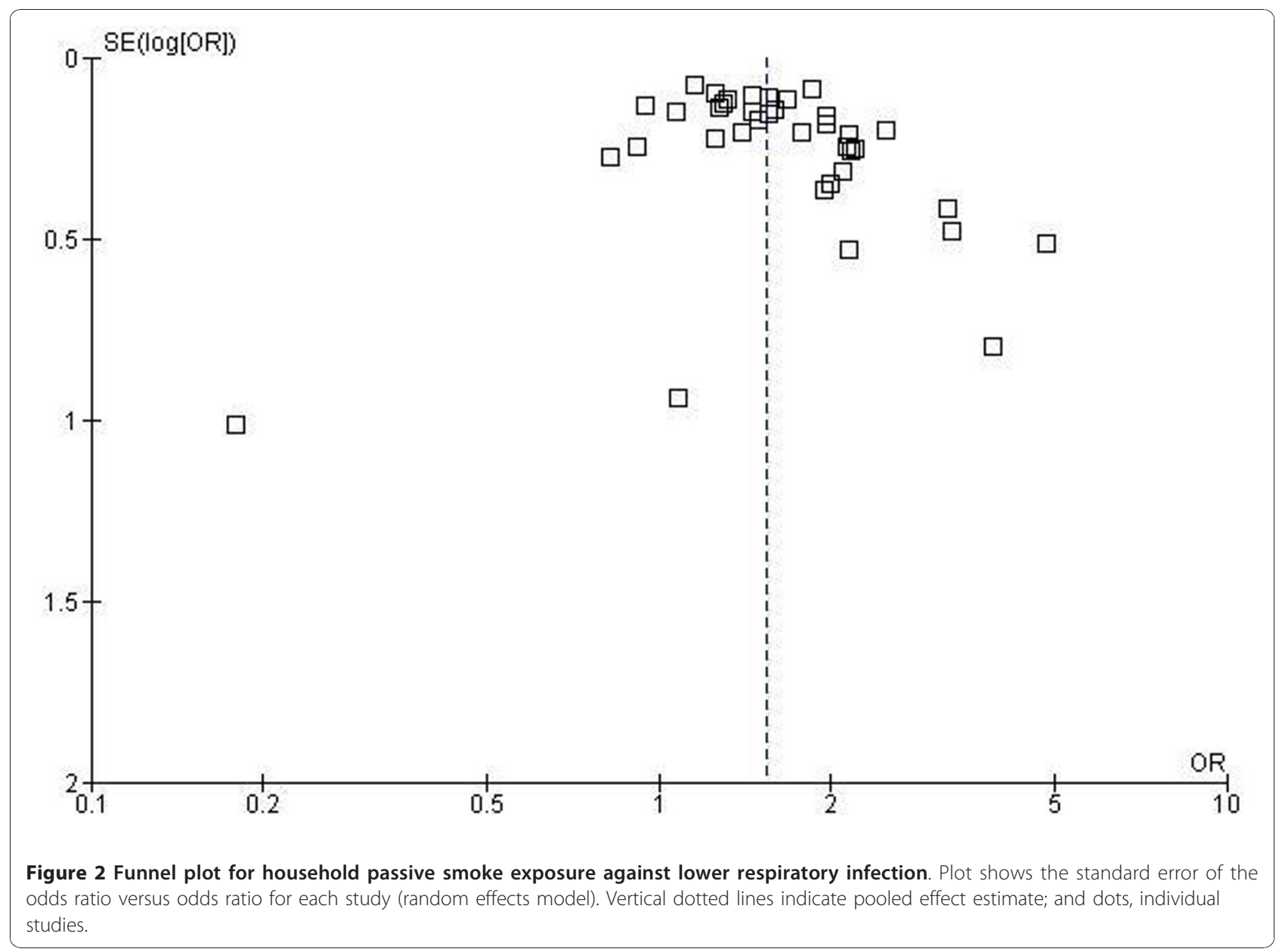




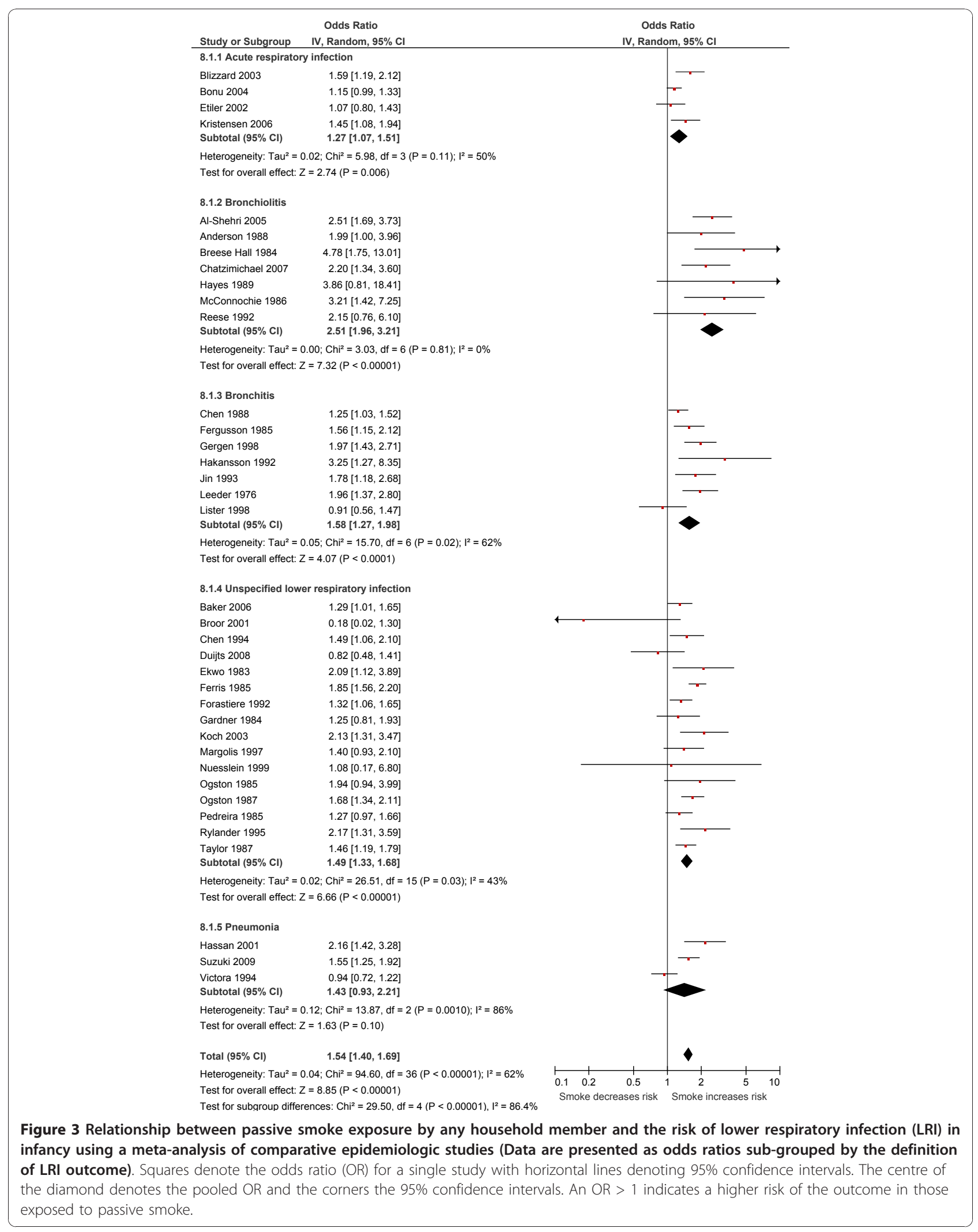


analysis $\left(I^{2}=62 \%\right)$. Sub-analysis based on the definition of outcome showed that the increased risk of disease was predominantly due to a strong association between household passive smoke exposure and bronchiolitis (OR 2.51, 95\% CI 1.96 to 3.21; 7 studies; Figure 3 ). Broadly similar, but lower increases in risk were estimated for all the other categories of LRI (ARI: OR 1.27, 95\% CI 1.07 to 1.51 ; 4 studies; bronchitis: OR $1.58,95 \%$ CI 1.27 to 1.98 ; 7 studies; ULRI: OR $1.49,95 \%$ CI, 1.33 to 1.68 ; 16 studies; pneumonia: OR $1.43,95 \%$ CI 0.93 to $2.21 ; 3$ studies). All pooled odds ratios were significant except for pneumonia which was imprecisely estimated. Sub-group analysis based on study design showed similar pooled estimates of increased disease risk (cohort studies: OR $1.47,95 \%$ CI 1.33 to 1.62 ; 17 studies; cross-sectional studies: OR $1.49,95 \%$ CI 1.28 to $1.74 ; 11$ studies; case-control studies: OR 2.01, 95\% CI 1.31 to 3.10; 9 studies). Similar pooled estimates were also seen for sub-group analyses stratified by ascertainment of smoking status, date of publication and methodological quality.

\section{Effects of smoking by both parents}

A pooled estimate of the 14 studies which defined exposure as both parents smoking demonstrated a statistically significant increase in the odds of LRI, by 1.62 (95\% CI 1.38 to 1.89; Figure 4). Moderate levels of heterogeneity were seen between the studies $\left(I^{2}=65 \%\right)$. Sub-group analysis based on the definition of outcome showed that the increased risk was again attributable in particular to a strong effect on the estimated risk of bronchiolitis (OR 3.12, 95\% CI 1.76 to 5.54; 2 studies; Figure 4), and also bronchitis (OR 2.26, 95\% CI 1.50 to 3.42; 2 studies; Figure 4). Pooled estimates for the other categories of LRI all identified statistically significant increases in risk (ARI: OR 1.29, 95\% CI 1.11 to 1.51 ; 2 studies; ULRI: OR $1.57,95 \%$ CI 1.37 to 1.80 ; 7 studies), again with the exception of pneumonia ( $\mathrm{p}=0.71$, 1 study). In a sub-group analysis based on the method of ascertainment of passive smoke exposure, studies that used biochemically validated measures were significantly more likely (test for sub-group differences, $\mathrm{p}=0.006$ ) to show an increased risk of LRI (OR 2.69, 95\% CI 1.75 to 4.13 ; 2 studies) than to studies that used self-reported data (OR 1.53, 95\% CI 1.31 to 1.78 ; 12 studies). Similar pooled results were seen when the studies were categorised by methodological quality, date of publication, and by study design.

\section{Effects of paternal smoking}

Meta-analysis of the 21 studies of paternal smoking demonstrated a statistically significant increase in the odds of LRI by 1.22 (95\% CI 1.10 to 1.35). Pooled estimates for each of the outcome categories showed similar effect estimates by disease definition; however, these effects were significant only for bronchitis (OR $1.29,95 \%$ CI 1.03 to 1.62 ; 3 studies) and unspecified lower respiratory infection (OR 1.26, 95\% CI 1.08 to $1.45 ; 13$ studies). In a sub-group analysis based on method of ascertainment of passive smoke exposure, similar pooled estimates for both self-reported (OR $1.24,95 \%$ CI 1.13 to $1.36 ; 17$ studies) and biologically validated (OR $1.26,95 \%$ CI 0.62 to $2.54 ; 4$ studies) measures were seen, although the latter was not statistically significant $(p=0.52)$. Similar pooled estimates were also shown for the sub-group analysis of methodological quality, study design and date of publication.

\section{Effects of pre-natal maternal smoking}

Pooled estimates from the ten studies of pre-natal maternal smoking showed a statistically significant increase in the odds of LRI by 1.24 (95\% CI 1.11 to 1.38). High levels of heterogeneity were seen between the studies $\left(I^{2}=77 \%\right)$. This effect was stronger in the single study of bronchitis as outcome (OR 2.44, 95\% CI 1.74 to 3.40); effects on ARI (OR 1.54, 95\% CI 1.12 to $2.11 ; 1$ study) and ULRI (OR $1.12,95 \%$ CI 1.04 to 1.21 ; 8 studies) were weaker. In a sub-group analysis based on method of ascertainment of passive smoke exposure, studies that used self-reported data showed a statistically significant increase in disease risk (OR $1.25,95 \%$ CI 1.11 to $1.40 ; 8$ studies), in contrast to studies that used biochemical validation (OR 1.07, 95\% CI 0.61 to $1.90 ; 2$ studies). Similar pooled estimates were shown for the sub-group analysis of methodological quality, and study design. All of the studies included in this exposure group were published after 1997.

\section{Effects of maternal smoking after birth}

Maternal smoking after birth was associated with a statistically significant increase in odds of LRI, by 1.58 (95\% CI 1.45 to 1.73 ; 31 studies; Figure 5 ). Sub-group analysis demonstrated a strong association between post-natal maternal smoking and bronchiolitis (OR 2.51, 95\% CI 1.58 to 3.97; 5 studies; Figure 5). Pooled estimates for the other categories of LRI were similar and significant (ARI: OR $1.59,95 \%$ CI 1.23 to $2.05 ; 3$ studies; bronchitis: OR 1.49, 95\% CI 1.25 to 1.78 ; 5 studies; ULRI: OR 1.64, 95\% CI 1.46 to $1.84 ; 17$ studies), with the exception of pneumonia ( $\mathrm{p}=0.87,2 \mathrm{stu}$ dies). Sub-group analysis based on study design showed similar pooled estimates of increased disease risk (cohort studies: OR 1.62, 95\% CI 1.46 to $1.79 ; 16$ studies; cross-sectional studies: OR 1.46, 95\% CI 1.18 to 1.80 ; 6 studies; case-control studies: OR $1.73,95 \%$ 


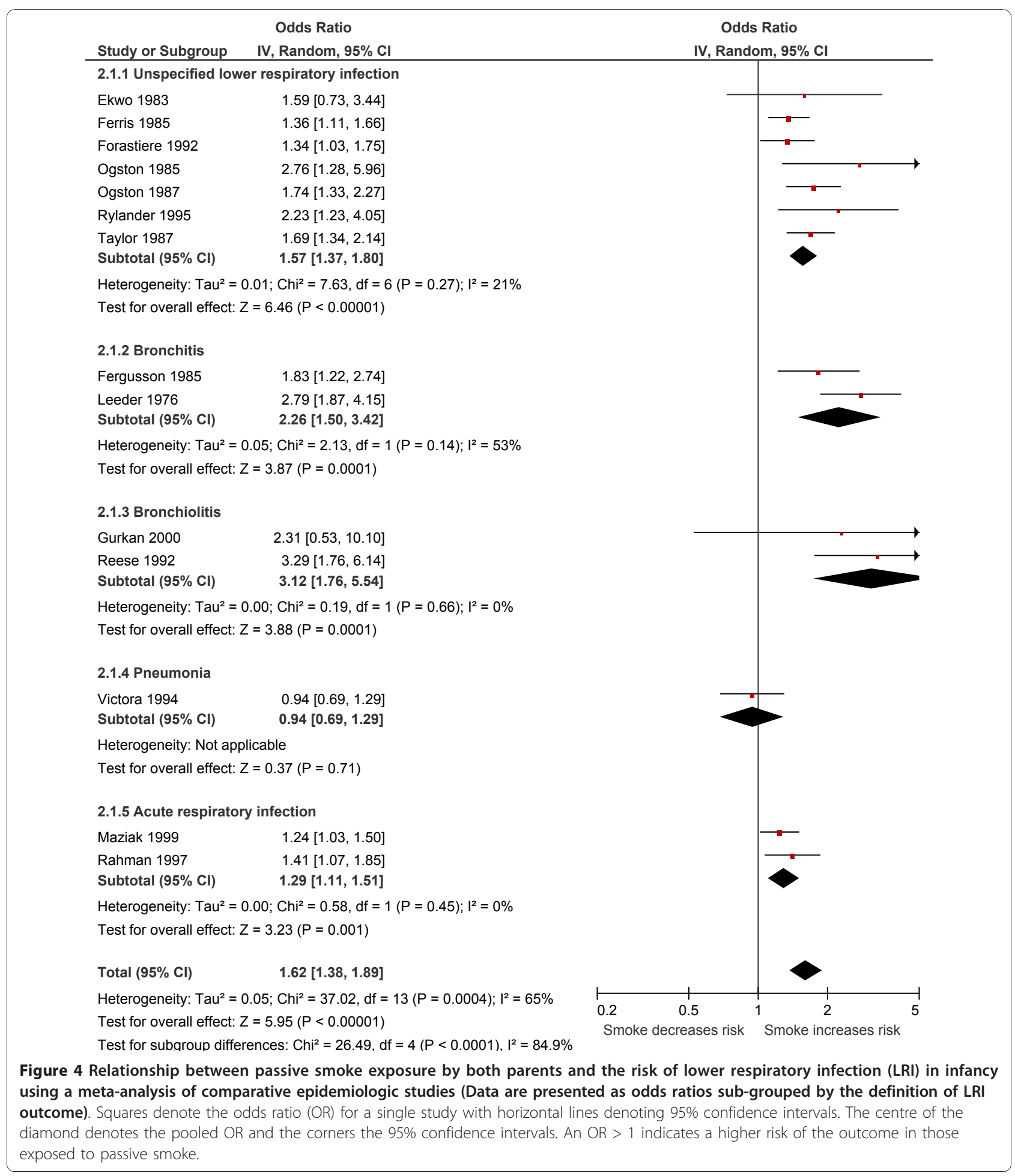

CI 1.23 to $2.44 ; 9$ studies). In a sub-group analysis based on method of ascertainment of passive smoke exposure similar pooled estimates for both selfreported (OR 1.60, 95\% CI 1.47 to $1.74 ; 26$ studies) and biologically validated (OR $1.58,95 \%$ CI 0.95 to
2.63; 5 studies) measures were seen, although the latter was not statistically significant. Similar pooled estimates were also shown for the sub-group analysis based on methodological quality and date of publication. 


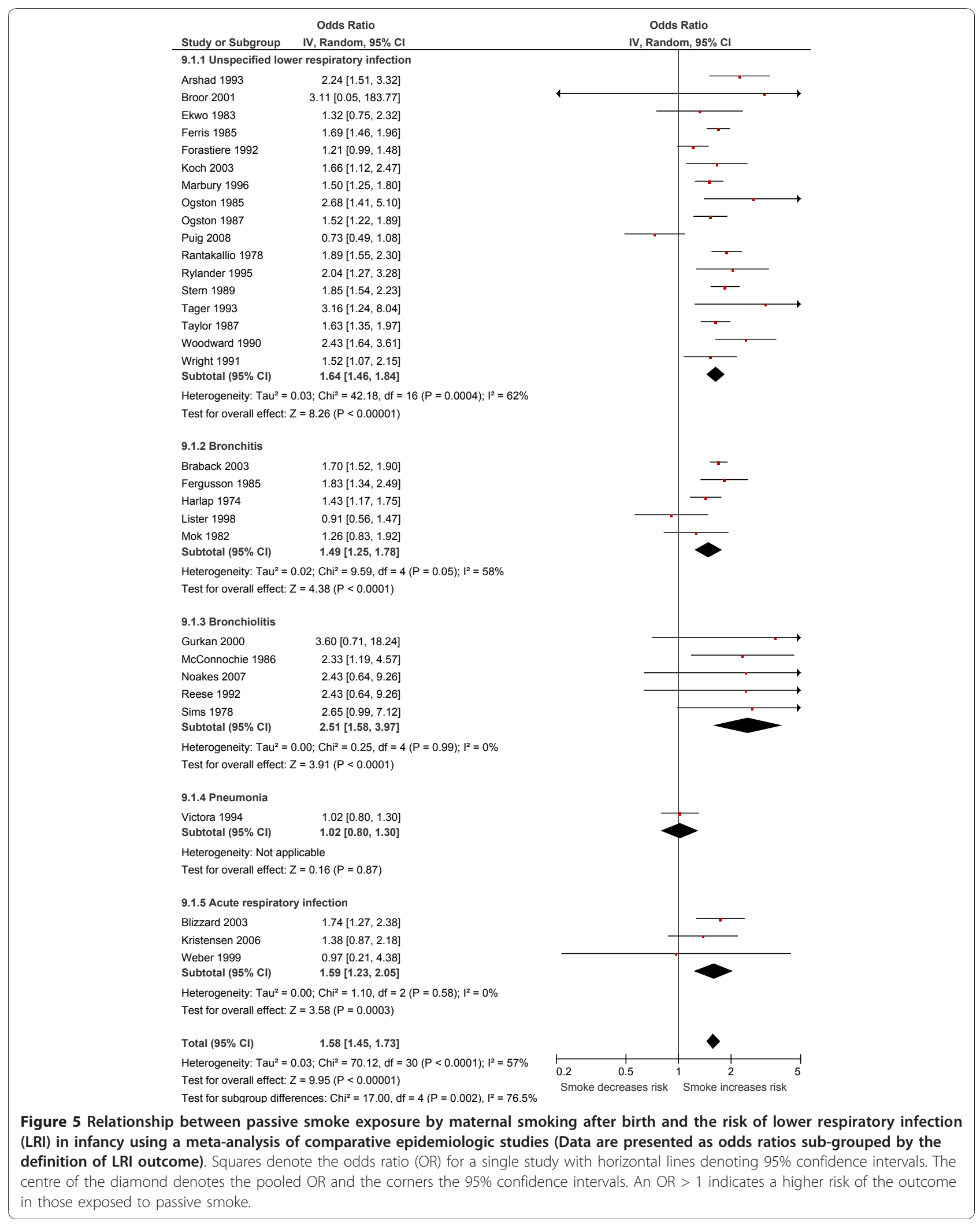




\section{Exposure-response relationships}

An assessment of the relation between amount of exposure and disease risk was included in 26 of the 60 papers studied, quantifying exposure in terms of the numbers of cigarettes per day smoked by the source of exposure, the mean daily cigarette exposure of the infant, or by the number of smokers within the household. A positive, but not necessarily significant association was identified in 25 studies and an inverse relationship in one.

\section{Discussion}

Passive smoking was recognised as a cause of lower respiratory infection in children in the US Surgeon General report of 2006 [1] and also in the UK Government SCOTH report [4]. Both reports drew on a series of systematic reviews and meta-analyses which for LRI originally included studies published up to 1997 [3], but was updated for the Surgeon General and SCOTH reports $[1,4]$ by the inclusion of papers published to the end of 2001. The number of relevant studies has increased substantially since the original systematic review was published however, and the updated systematic review and meta-analysis described in the present study combines data from 31 of the studies used in the original review [3] with a further 29 studies published since 1997 . This study demonstrates significant increases in the risk of LRI for smoking by the mother, father, both parents, and by any household member. These effects are typically strongest for bronchiolitis, and particularly in relation to maternal smoking. Pre-natal maternal smoking, which would be expected to be confounded with post-natal smoking because the majority of mothers who smoke through pregnancy continue to smoke post-delivery, also had an effect on LRI risk but this was weaker than most post-natal effect estimates. This indicates that postnatal tobacco smoke exposure, rather than exposure to blood-borne tobacco toxins in utero, is more likely to be the underlying cause of lower respiratory infections such as bronchiolitis in infancy.

The larger number of studies now available allowed us to explore effects on individual diagnoses included in the LRI category, and we found that the effect of passive smoking was typically strongest for bronchiolitis, and in some cases bronchitis. The magnitudes of the effects we detected were broadly consistent with the original review [3] though slightly smaller for post-natal maternal smoking (1.58 versus 1.72 ) and paternal smoking (1.22 versus 1.29$)$. This may indicate that publication bias could have increased the magnitude of these earlier estimates; however, our funnel plot analysis for passive smoke exposure by any household member indicated that publication bias is unlikely to have had a marked effect on the results of the present study.

Our findings are likely to be representative estimates of the true effects of passive smoking on the risk of LRI in infancy since they are based on results of a comprehensive search, including data identified through hand searching of reference lists and previous reviews. However, there are limitations to this review. We elected to keep methods consistent with the original strategy [3] and only included studies written in English in the meta-analyses. Additionally, we were inevitably limited in the range of confounding factors that could be adjusted for in our analyses. Although the high quality studies generally adjusted for maternal age and socioeconomic status; other potential confounders, such as smoking by other individuals in the household, were not consistently adjusted for in the analyses of the individual effects of paternal and maternal smoking.

\section{Conclusions}

This study thus confirms that exposure to all types of passive smoke, in particular maternal smoking, causes a statistically significant increase in the risk of infants developing lower respiratory infections in the first two years of life, and provides further precision in the estimates of the magnitudes of those effects in relation to differences in the source and extent of passive smoking in the home. Importantly, the study also identifies clinically-diagnosed bronchiolitis as a particular consequence of exposure, and one which can cause significant morbidity and in some cases mortality. Lower respiratory infections are common in infants, resulting, for example, in over 33,000 hospital admissions in infants aged under two years in England alone, where about 10\% are estimated to be due to passive smoke exposure [5]. These additional hospital admissions are a significant public health burden all of which are avoidable. It is thus clear that there is a need for renewed efforts to prevent the exposure of infants to passive smoke, both during and after pregnancy.

\section{Additional material}

Additional file 1: Summary of studies included in the meta-analysis

The data provided represent a summary of each of the studies included in the updated meta-analysis.

\section{Acknowledgements}

This work was supported by project grant C1512/A11160 from Cancer Research UK, and by core funding to the UK Centre for Tobacco Control Studies http://www.ukctcs.org from the British Heart Foundation, Cancer Research UK, Economic and Social Research Council, Medical Research 
Council, and the Department of Health, under the auspices of the UK Clinical Research Collaboration.

\section{Author details}

1UK Centre for Tobacco Control Studies, Division of Epidemiology and Public Health, University of Nottingham, Clinical Sciences Building, Nottingham City Hospital, Nottingham, NG5 1PB, UK. ²Division of Community Health Sciences, St George's University of London, Cranmer Terrace, London, SW17 ORE, UK.

\section{Authors' contributions}

LLJ reviewed the full text articles, extracted data and wrote the initial draft of the manuscript. AH conducted the literature search, reviewed titles, abstracts and full text articles and contributed to the extraction of data. TM reviewed titles and abstracts and provided critical revision of the manuscript DGC and JB contributed to the critical revision of the manuscript. JLB reviewed titles, abstracts and full text articles, extracted data and conducted the statistical analysis and provided critical revision of the manuscript. All authors read and approved the final manuscript.

\section{Competing interests}

The authors declare that they have no competing interests.

Received: 13 October 2010 Accepted: 10 January 2011

Published: 10 January 2011

\section{References}

1. U.S. Department of Health and Human Services: The Health Consequences of Involuntary Exposure to Tobacco Smoke: A Report of the Surgeon General. Centers for Disease Control and Prevention, National Center for Chronic Disease Prevention and Health Promotion, Office on Smoking and Health 2006

2. Department of Health. Department of Health and Social Services Northern Ireland, The Scottish Office Department of Health and Welsh Office: Report of the Scientific Committee on Tobacco and Health. London: The Stationery Office; 1998

3. Strachan DP, Cook DG: Health effects of passive smoking. 1. Parental smoking and lower respiratory illness in infancy and early childhood. Thorax 1997, 52:905-914.

4. Scientific Committee on Tobacco and Health (SCOTH): Secondhand smoke: Review of evidence since 1998. Update of evidence on health effects of secondhand smoke. London: Department of Health; 2004.

5. Royal College of Physicians: Passive smoking and children. A report by the Tobacco Advisory Group. London: RCP; 2010.

6. Newcastle-Ottawa scale (NOS) for assessing the quality of non randomised studies in meta-analysis. [http://www.ohri.ca/programs/ clinical epidemiology/oxford.htm]

7. DerSimonian R, Laird N: Meta-analysis in clinical trials. Control Clin Trials 1986, 7:177-188

8. Higgins JP, Thompson SG: Quantifying heterogeneity in a meta-analysis. Stat Med 2002, 21:1539-1558.

9. Stroup DF, Berlin JA, Morton SC, Olkin I, Williamson GD, Rennie D, Moher D Becker BJ, Sipe TA, Thacker SB: Meta-analysis of observational studies in epidemiology: a proposal for reporting. Meta-analysis Of Observational Studies in Epidemiology (MOOSE) group. JAMA 2000, 283:2008-2012.

10. Bisgaard $H$, Dalgaard $P$, Nyboe J: Risk factors for wheezing during infancy. A study of 5,953 infants. Acta Paediatr Scand 1987, 76:719-726.

11. Burr ML, Miskelly FG, Butland BK, Merrett TG, Vaughan-Williams E: Environmental factors and symptoms in infants at high risk of allergy. $J$ Epidemiol Community Health 1989, 43:125-132.

12. Elder DE, Hagan R, Evans SF, Benninger HR, French NP: Recurrent wheezing in very preterm infants. Arch Dis Child Fetal Neonatal Ed 1996, 74:F165-171.

13. Halken S, Host A, Husby S, Hansen LG, Osterballe O, Nyboe J: Recurrent wheezing in relation to environmental risk factors in infancy. A prospective study of 276 infants. Allergy 1991, 46:507-514.

14. Lucas A, Brooke OG, Cole TJ, Morley R, Bamford MF: Food and drug reactions, wheezing, and eczema in preterm infants. Arch Dis Child 1990, 65:411-415.

15. Martinez FD, Wright AL, Taussig LM, Holberg CJ, Halonen M, Morgan WJ: Asthma and wheezing in the first six years of life. The Group Health Medical Associates. N Engl J Med 1995, 332:133-138.
16. Richards GA, Terblanche AP, Theron AJ, Opperman L, Crowther G, Myer MS, Steenkamp KJ, Smith FC, Dowdeswell R, van der Merwe CA, et al: Health effects of passive smoking in adolescent children. S Afr Med J 1996, 86:143-147.

17. Arshad SH, Stevens M, Hide DW: The effect of genetic and environmental factors on the prevalence of allergic disorders at the age of two years. Clin Exp Allergy 1993, 23:504-511.

18. Baker RJ, Hertz-Picciotto I, Dostal M, Keller JA, Nozicka J, Kotesovec F, Dejmek J, Loomis D, Sram RJ: Coal home heating and environmental tobacco smoke in relation to lower respiratory illness in Czech children, from birth to 3 years of age. Environ Health Perspect 2006, 114:1126-1132.

19. Blizzard L, Ponsonby A-L, Dwyer T, Venn A, Cochrane JA: Parental smoking and infant respiratory infection: how important is not smoking in the same room with the baby? Am J Public Health 2003, 93:482-488.

20. Braback L, Bjor O, Nordahl G: Early determinants of first hospital admissions for asthma and acute bronchitis among Swedish children. Acta Paediatrica 2003, 92:27-33.

21. Carroll KN, Gebretsadik T, Griffin MR, Dupont WD, Mitchel EF, Wu P, Enriquez R, Hartert TV: Maternal asthma and maternal smoking are associated with increased risk of bronchiolitis during infancy.[see comment]. Pediatrics 2007, 119:1104-1112.

22. Duijts L, Jaddoe WW, Hofman A, Steegers EAP, Mackenbach JP, de Jongste JC, Moll HA: Maternal smoking in pre-natal and early post-natal life and the risk of respiratory tract infections in infancy. The Generation R study. Eur J Epidemiol 2008, 23:547-555.

23. Etiler N, Velipasaoglu S, Aktekin M: Incidence of acute respiratory infections and the relationship with some factors in infancy in Antalya, Turkey. Pediatr Int 2002, 44:64-69.

24. Fergusson DM, Horwood L: Parental smoking and respiratory illness during early childhood: a six-year longitudinal study. Pediatr Pulmonol 1985, 1:99-106

25. Gardner G, Frank AL, Taber LH: Effects of social and family factors on viral respiratory infection and illness in the first year of life. $J$ Epidemiol Community Health 1984, 38:42-48.

26. Haberg SE, Stigum H, Nystad W, Nafstad P: Effects of pre- and post-natal exposure to parental smoking on early childhood respiratory health. Am J Epidemiol 2007, 166:679-686.

27. Harlap S, Davies AM: Infant admissions to hospital and maternal smoking Lancet 1974, 1:529-532

28. Jin C, Rossignol AM: Effects of passive smoking on respiratory illness from birth to age eighteen months, in Shanghai, People's Republic of China. J Pediatr 1993, 123:553-558.

29. Koch A, Molbak K, Homoe P, Sorensen P, Hjuler T, Olesen ME, Pejl J, Pedersen FK, Olsen OR, Melbye M: Risk factors for acute respiratory tract infections in young Greenlandic children. Am J Epidemiol 2003, 158:374-384.

30. Koehoorn M, Karr CJ, Demers PA, Lencar C, Tamburic L, Brauer M: Descriptive epidemiological features of bronchiolitis in a populationbased cohort. Pediatrics 2008, 122:1196-1203.

31. Kristensen IA, Olsen J: Determinants of acute respiratory infections in Soweto-a population-based birth cohort. S Afr Med J 2006, 96:633-640.

32. Latzin P, Frey U, Roiha HL, Baldwin DN, Regamey N, Strippoli MPF, Zwahlen M, Kuehni CE, Swiss Paediatric Respiratory Research G: Prospectively assessed incidence, severity, and determinants of respiratory symptoms in the first year of life. Pediatr Pulmonol 2007, 42:41-50.

33. Leeder SR, Corkhill R, Irwig LM, Holland WW, Colley JR: Influence of family factors on the incidence of lower respiratory illness during the first year of life. Br J Prev Soc Med 1976, 30:203-212.

34. Marbury MC, Maldonado G, Waller L: The indoor air and children's health study: methods and incidence rates. Epidemiology 1996, 7:166-174.

35. Margolis PA, Keyes LL, Greenberg RA, Bauman KE, LaVange LM: Urinary cotinine and parent history (questionnaire) as indicators of passive smoking and predictors of lower respiratory illness in infants. Pediatr Pulmonol 1997, 23:417-423.

36. Noakes P, Taylor A, Hale J, Breckler L, Richmond P, Devadason SG, Prescott SL: The effects of maternal smoking on early mucosal immunity and sensitization at 12 months of age. Pediatr Allergy Immunol 2007, 18:118-127.

37. Nuesslein $\mathrm{TG}$, Beckers $\mathrm{D}$, Rieger $\mathrm{CH}$ : Cotinine in meconium indicates risk for early respiratory tract infections. Hum Exp Toxicol 1999, 18:283-290. 
38. Ogston SA, Florey CD, Walker CH: The Tayside infant morbidity and mortality study: effect on health of using gas for cooking. BMJ 1985, 290:957-960.

39. Ogston SA, Florey $\mathrm{CD}$, Walker $\mathrm{CH}$ : Association of infant alimentary and respiratory illness with parental smoking and other environmental factors. J Epidemiol Community Health 1987, 41:21-25.

40. Pedreira FA, Guandolo VL, Feroli EJ, Mella GW, Weiss IP: Involuntary smoking and incidence of respiratory illness during the first year of life. Pediatrics 1985, 75:594-597.

41. Puig C, Sunyer J, Garcia-Algar O, Munoz L, Pacifici R, Pichini S, Vall O: Incidence and risk factors of lower respiratory tract illnesses during infancy in a Mediterranean birth cohort. Acta Paediatrica 2008, 97:1406-1411.

42. Rahman MM, Rahman AM: Prevalence of acute respiratory tract infection and its risk factors in under five children. Bangladesh Med Res Counc Bull 1997, 23:47-50

43. Rantakallio P: Relationship of maternal smoking to morbidity and mortality of the child up to the age of five. Acta Paediatr Scand 1978, 67:621-631.

44. Tager IB, Hanrahan JP, Tosteson TD, Castile RG, Brown RW, Weiss ST, Speizer FE: Lung function, pre- and post-natal smoke exposure, and wheezing in the first year of life. Am Rev Respir Dis 1993, 147:811-817.

45. Taylor B, Wadsworth J: Maternal smoking during pregnancy and lower respiratory tract illness in early life. Arch Dis Child 1987, 62:786-791.

46. Wright AL, Holberg C, Martinez FD, Taussig LM: Relationship of parental smoking to wheezing and nonwheezing lower respiratory tract illnesses in infancy. Group Health Medical Associates. J Pediatr 1991, 118:207-214.

47. Ruskamp J, Smit H, Rovers M, Hoekstra M, Schilder A, Brunekreef B, Wijga A, Kerkhof $\mathrm{M}$, de Jongste J, Sanders $\mathrm{E}$ : Neonatal total IgE and respiratory tract infections in children with intrauterine smoke exposure. Arch Dis Child 2010, 95:427-431.

48. Al-Shehri MA, Sadeg A, Quli K: Bronchiolitis in Abha, Southwest Saudi Arabia: viral etiology and predictors for hospital admission. West Afr $J$ Med 2005, 24:299-304

49. Anderson LJ, Parker RA, Strikas RA, Farrar JA, Gangarosa EJ, Keyserling HL, Sikes RK: Day-care center attendance and hospitalization for lower respiratory tract illness. Pediatrics 1988, 82:300-308.

50. Breese Hall C, Hall WJ, Gala CL, MaGill FB, Leddy JP: Long-term prospective study in children after respiratory syncytial virus infection. J Pediatr 1984, 105:358-364

51. Broor S, Pandey RM, Ghosh M, Maitreyi RS, Lodha R, Singhal T, Kabra SK: Risk factors for severe acute lower respiratory tract infection in underfive children. Indian Pediatr 2001, 38:1361-1369.

52. El-Sawy IH, Nasr FMK, Mowafy EWE, Sharaki OAM, Bakey AMA: Passive smoking and lower respiratory tract illnesses in children. Eastern Mediterranean Health Journal 1997, 3:425-434.

53. Gurkan F, Kiral A, Dagli E, Karakoc F: The effect of passive smoking on the development of respiratory syncytial virus bronchiolitis. Eur J Epidemiol 2000, 16:465-468.

54. Hassan MK, Al-Sadoon I: Risk factors for severe pneumonia in children in Basrah. Trop Doct 2001, 31:139-141

55. Hayes EB, Hurwitz ES, Schonberger LB, Anderson LJ: Respiratory syncytial virus outbreak on American Samoa. Evaluation of risk factors. Am J Dis Child 1989, 143:316-321.

56. McConnochie KM, Roghmann KJ: Parental smoking, presence of older siblings, and family history of asthma increase risk of bronchiolitis. Am J Dis Child 1986, 140:806-812.

57. Mok JY, Simpson $\mathrm{H}$ : Outcome of acute lower respiratory tract infection in infants: preliminary report of seven-year follow-up study. BMJ 1982, 285:333-337

58. Rylander E, Pershagen G, Eriksson M, Bermann G: Parental smoking, urinary cotinine, and wheezing bronchitis in children. Epidemiology 1995, 6:289-293.

59. Sims DG, Downham MA, Gardner PS, Webb JK, Weightman D: Study of 8year-old children with a history of respiratory syncytial virus bronchiolitis in infancy. BMJ 1978, 1:11-14.

60. Victora CG, Fuchs SC, Flores JA, Fonseca W, Kirkwood B: Risk factors for pneumonia among children in a Brazilian metropolitan area. Pediatrics 1994, 93:977-985.

61. Weber MW, Milligan P, Hilton S, Lahai G, Whittle H, Mulholland EK, Greenwood BM: Risk factors for severe respiratory syncytial virus infection leading to hospital admission in children in the Western Region of The Gambia. Int J Epidemiol 1999, 28:157-162.

62. Woodward A, Douglas RM, Graham NM, Miles H: Acute respiratory illness in Adelaide children: breast feeding modifies the effect of passive smoking. J Epidemiol Community Health 1990, 44:224-230.

63. Bonu S, Rani M, Jha P, Peters DH, Nguyen SN: Household tobacco and alcohol use, and child health: an exploratory study from India. Health Policy 2004, 70:67-83

64. Chatzimichael A, Tsalkidis A, Cassimos D, Gardikis S, Tripsianis G, Deftereos S, Ktenidou-Kartali S, Tsanakas I: The role of breastfeeding and passive smoking on the development of severe bronchiolitis in infants. Minerva Pediatr 2007, 59:199-206.

65. Chen Y: Environmental tobacco smoke, low birth weight, and hospitalization for respiratory disease. Am J Respir Crit Care Med 1994, 150:54-58

66. Chen Y, Li WX, Yu SZ, Qian WH: Chang-Ning epidemiological study of children's health: I: Passive smoking and children's respiratory diseases. Int J Epidemiol 1988, 17:348-355.

67. Ekwo EE, Weinberger MM, Lachenbruch PA, Huntley WH: Relationship of parental smoking and gas cooking to respiratory disease in children. Chest 1983, 84:662-668.

68. Ferris BG Jr, Ware JH, Berkey CS, Dockery DW, Spiro A, Speizer FE: Effects of passive smoking on health of children. Environ Health Perspect 1985, 62:289-295.

69. Forastiere F, Corbo GM, Michelozzi P, Pistelli R, Agabiti N, Brancato G, Ciappi G, Perucci CA: Effects of environment and passive smoking on the respiratory health of children. Int J Epidemiol 1992, 21:66-73.

70. Gergen PJ, Fowler JA, Maurer KR, Davis WW, Overpeck MD: The burden of environmental tobacco smoke exposure on the respiratory health of children 2 months through 5 years of age in the United States: Third National Health and Nutrition Examination Survey, 1988 to 1994. Pediatrics 1998, 101:E8.

71. Lister SM, Jorm LR: Parental smoking and respiratory illnesses in Australian children aged 0-4 years: ABS 1989-90 National Health Survey results. Aust N Z J Public Health 1998, 22:781-786.

72. Maziak W, Mzayek F, al-Musharref M: Effects of environmental tobacco smoke on the health of children in the Syrian Arab Republic. East Mediterr Health J 1999, 5:690-697.

73. Reese AC, James IR, Landau LI, Lesouef PN: Relationship between urinary cotinine level and diagnosis in children admitted to hospital. Am Rev Respir Dis 1992, 146:66-70.

74. Stern B, Raizenne M, Burnett R: Respiratory effects of early childhood exposure to passive smoke. Environ Int 1989, 15:29-34

75. Suzuki M, Thiem VD, Yanai H, Matsubayashi T, Yoshida LM, Tho LH, Minh $T$, Anh DD, Kilgore PE, Ariyoshi K: Association of environmental tobacco smoking exposure with an increased risk of hospital admissions for pneumonia in children under 5 years of age in Vietnam. Thorax 2009, 64:484-489.

76. Hakansson A, Carlsson B: Maternal cigarette smoking, breast-feeding, and respiratory tract infections in infancy. A population-based cohort study. Scand J Prim Health Care 1992, 10:60-65.

doi:10.1186/1465-9921-12-5

Cite this article as: Jones et al:: Parental and household smoking and the increased risk of bronchitis, bronchiolitis and other lower respiratory infections in infancy: systematic review and meta-analysis. Respiratory Research 2011 12:5. 